\title{
Automatic Detection of Fractures during Tensile Testing Using Vibroacoustic Sensors ${ }^{\dagger}$
}

\author{
Joao Vitor Pimentel 1,*, Rolf Klemm ${ }^{1}$, Münip Dalgic ${ }^{2}$, Andree Irretier ${ }^{2}$ and Karl-Ludwig Krieger ${ }^{1}$ \\ 1 Institute of Electrodynamics and Microelectronics (ITEM), University of Bremen, Otto-Hahn-Allee, \\ 28359 Bremen, Germany; rklemm@uni-bremen.de (R.K.); krieger@uni-bremen.de (K.-L.K.) \\ 2 IWT Stiftung Institut für Werkstofftechnik, Paul-Feller-Str. 1, 28199 Bremen, Germany; \\ dalgic@iwt-bremen.de (M.D.); irretier@mpa-bremen.de (A.I.) \\ * Correspondence: jpimentel@uni-bremen.de \\ + Presented at the 3rd International Electronic Conference on Sensors and Applications, 15-30 November 2016; \\ Available online: https://sciforum.net/conference/ecsa-3.
}

Published: 14 November 2016

\begin{abstract}
The detection of structure-borne sound can be used to monitor the structural health of solid structures and machine parts. One way to achieve such an implementation is to place vibroacoustic sensors in contact with the structure. The sensors will typically generate an electric signal in response to the acoustic emissions caused by specific events, such as fractures in the structure. In this paper, vibroacoustic sensors were used to detect structure-borne sound during static tensile testing of metallic samples until complete fracture. The samples used were sections of longitudinal beams made of S700 MC steel. Two different types of piezoelectric sensors were used: PVDF film sensors glued to the sample, and ceramic sensors attached to the sample with a magnet adapter. The bandwidth of the signals was expected from previous studies to be of up to $2 \mathrm{MHz}$. Simultaneously, force and displacement were measured at the testing machine. An algorithm was written to process the data acquired from the piezo elements and automatically detect relevant events via a simple comparison with a pre-defined voltage threshold to detect signals above the background noise level. The comparison of the detected events with the force measurements from the tensile test showed a very strong correlation between actual fractures (both the initial fracture and its posterior propagation) and the automatic classification carried out by the algorithm. Thus, the vibroacoustic sensor could with little calibration substitute the other standard measurement systems.
\end{abstract}

Keywords: vibroacoustic piezoelectric sensors; tensile test

(C) 2016 by the authors. Licensee MDPI, Basel, Switzerland. This article is an open access article distributed under the terms and conditions of the Creative Commons Attribution (CC BY) license (http://creativecommons.org/licenses/by/4.0/). 